\title{
A combination of terrestrial laser-scanning point clouds and the thrust network analysis approach for structural modelling of masonry vaults
}

\author{
Maria Grazia D'Urso' ${ }^{1}$, Valerio Manzari², Barbara Marana ${ }^{3}$ \\ 1 Department of Engineering and Applied Sciences, University of Bergamo, Bergamo, Italy \\ ${ }^{2}$ Department of Civil and Mechanical Engineering, University of Cassino and Southern Lazio, Cassino, Italy \\ ${ }^{3}$ Department of Engineering and Applied Sciences, University of Bergamo, Bergamo, Italy
}

\section{ABSTRACT}

Terrestrial laser-scanning (TLS) is well suited to surveying the geometry of monumental complexes, often realised with highly irregular materials and forms. This paper addresses various issues related to the acquisition of point clouds via TLS and their elaboration aimed at developing structural models of masonry vaults. This structural system, which exists in numerous artifacts and historical buildings, has the advantages of good static and functional behaviour, reduced weight, good requisites of insulation, and aesthetic quality. Specifically, using TLS, we create a geometric model of the ancient masonry church, S. Maria della Libera, in Aquino, largely characterised by naves featuring cross vaults and previously used as a case study in the paper entitled 'Terrestrial laser-scanning point-clouds for modeling masonry vaults', presented at the 2019 IMEKO TC-4 International Conference on Metrology for Archaeology and Cultural Heritage. The results of the TLS survey are used as input for a structural analysis based on the thrust network analysis. This recent methodology is used for modelling masonry vaults as a discrete network of forces in equilibrium with gravitational loads. It is demonstrated that the proposed approach is both effective and robust in terms of assessing not only the safety conditions of existing masonry vaults, the actual geometry of which significantly influences the safety level, but also to design new ones.

\section{Section: RESEARCH PAPER}

Keywords: Masonry vault; laser-scanning; thrust network analysis; point cloud; geometric configuration; structural analysis; equilibrium of nodes

Citation: Maria Grazia D'Urso, Valerio Manzari, Barbara Marana, A combination of terrestrial laser-scanning point clouds and the thrust network analysis approach for structural modelling of masonry vaults, Acta IMEKO, vol. 10, no. 1, article 34, March 2021, identifier: IMEKO-ACTA-10 (2021)-01-34

Editor: Ioan Tudosa, University of Sannio, Italy

Received January 2, 2021; In final form February 15, 2021; Published March 2021

Copyright: This is an open-access article distributed under the terms of the Creative Commons Attribution 3.0 License, which permits unrestricted use, distribution, and reproduction in any medium, provided the original author and source are credited.

Funding: This work was supported by the Italian Ministry of Education, University and Research (MIUR)

Corresponding author: Maria Grazia D'Urso, e-mail: mariagrazia.durso@unibg.it

\section{INTRODUCTION}

In this paper, we present a review on the integration of terrestrial laser scanning (TLS) point clouds acquired via the most frequently employed survey techniques, as well as an innovative method for studying historical masonry vaults.

The study of historical buildings continues to face significant difficulties related to computational effort, the scarcity of input data, and the limited realism of the attendant methods. Studies oriented toward the conservation and restoration of historical structures exploit structural analysis as a means of better understanding the genuine structural features of the building in view of characterising its present condition and the causes of the existing damage, determining the actual structural safety in terms of a variety of factors (e.g. gravity, soil settlements, wind, and earthquakes), and determining the necessary remedial measures [1]-[3].

Historical structures are often characterised by a highly complex geometry composed of various straight or curved members, combining the curved 1D members (arches, flying arches) with both 2D (vaults, domes) and 3D members (fillings, etc.). In fact, the geometry is one of the most crucial aspects of investigation given the complex combination of comparatively slender members with far larger members (e.g. massive piers, walls buttresses, foundations). As such, the investigation of the geometry is perhaps one of the greatest challenges faced by analysts. 
Historical structures may have experienced (and continue to experience) various phenomena of a very different nature, including gravity forces, earthquakes, and environmental effects (thermal effects, chemical or physical attack), as well as various anthropogenic actions such as architectural alterations, intentional destruction, and inadequate restorations. Many of these actions also need to be characterised in terms of time, with some cyclic and repetitive (accumulating significant effects in the long term), others developing gradually over extremely long periods of time, and others still associated with long return periods. In many cases, they may be influenced by historical contingency and uncertain (or at least, insufficiently known) historical facts.

The existing general alterations may significantly affect the response of the structure to be modelled, and, hence, the realism and accuracy of the prediction of the actual performance and capacity. Damage encompasses aspects such as mechanical cracking, material decay (due to chemical or physical attack), or a variety of other phenomena affecting the original capacity of the materials and structural members.

Its history is an essential aspect of a building and this must be taken in account and integrated within the model. The following effects linked to history may have had an impact on both the structural response and the existing damage: the construction process, any architectural alterations and additions, destruction due to conflicts (e.g. wars) or natural disasters (earthquakes, floods, fires), and various long-term decay or damage-inducing phenomena. In fact, the history as a whole constitutes a crucial source of knowledge. In numerous cases, the historical performance of the building can be engineered to reach conclusions on its structural performance and strength. For example, the performance exhibited during past earthquakes can be considered in order to improve the understanding of the antiseismic capacity. In fact, the history of the building constitutes a unique experience occurring on a real scale of space and time. As such, the knowledge of the historical performance can compensate for the aforementioned data insufficiency [4].

The most frequently employed survey techniques for capturing the geometry of buildings, also applied in the field of cultural heritage preservation, include both terrestrial and remote photogrammetry as well as TLS. Approaches based on the acquisition of images aimed at 3D modelling have recently become the subject of significant studies and research in various different areas [5]-[7].

The TLS technique presents a non-contact and non-intrusive technique that allows for digitally acquiring the shape of objects in a rapid and accurate way. The attendant research provides several examples of $3 \mathrm{D}$ point clouds acquired for detailed structural digital models, which represents a particularly relevant issue in the case of masonry structures, where geometry plays a crucial role in the comparative degree of safety [8].

Nowadays, starting from an accurate 3D model derived from laser scanning measures, it is possible to implement a building information modelling (BIM) approach that allows for managing the entire project in a consistent and optimal manner.

In fact, the laser scan techniques, such as TLS, which encompass scan-to-BIM among other processes, present a valuable prerequisite for BIM modelling, since they can support geometric and spatial data that can be acquired, organised, and managed to satisfy the required project scale. One single database ensures the quality of the results due to the direct link among the shapes, the information, and the project documentation [9], [10]. Specifically, 3D modelling becomes important when these

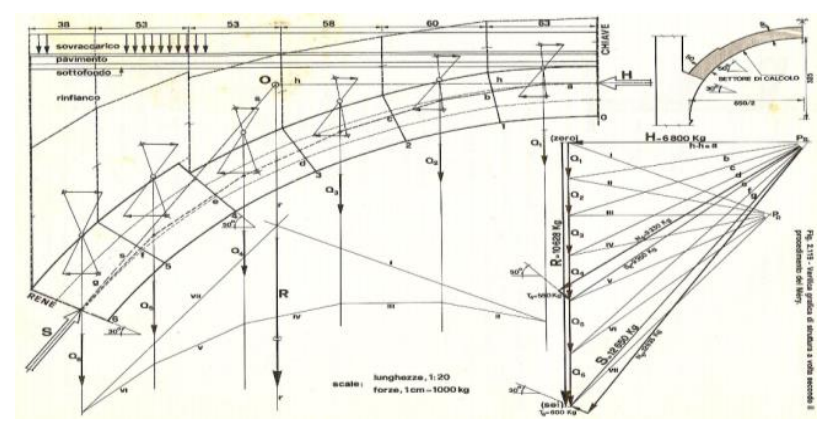

Figure 1. Mery's method: internal forces by means of a funicular polygon.

models are adopted for structural engineering purposes [11].

This is the case, for example, for masonry structures and vaults, the structural safety assessment of which involves either meshing them as a collection of finite elements, as in the traditional finite element method, or as a set of nodes connected by branches, as in the more recent thrust network analysis (TNA) approach [8]. Given the recent emergence of this approach, we first briefly illustrate its theoretical background and basic assumptions, largely to emphasise its flexibility and how the geometric data required as input naturally matches the output of TLS surveys.

Once the theoretical background and the state of art of the TNA method have been illustrated in the section 2, the basics of the TNA are dealt with in section 3. Section 4 describes the study case referred to the medieval Church of S. Maria della Libera, in Aquino for which the safety assessment of the cross vaults has been carried out. The related results are illustrated and commented in section 5. Finally the conclusions are summarized in section 6 .

\section{THEORETICAL BACKGROUND}

Nowadays, finite element (FEM) analysis can be regarded as the most effective numerical technique for structural analysis since, unlike traditional static analysis, it allows for i) providing a 3D model of geometrically complex structures, ii) managing the characteristic parameters of the materials employed in the model, and iii) performing different analyses (linear, non-linear, dynamical, etc.) on the same geometry.

However, in the case of historical and monumental masonry structures, FEM analysis does not present the best option since it is difficult to ascertain the characteristics of the materials and the effects induced by the interventions previously performed on the structure.

An alternative effective approach to FEM is the TNA approach, a fairly recent methodology that is briefly described in the sequel [12]-[17]. This method can be regarded as an automated and computerised variant of Mery's method, which is used for hand calculations of masonry arches (Figure 1).

Specifically, TNA is used to model masonry vaults as a discrete network of branches, subjected only to compressive forces in equilibrium with the gravitational loads. Originally devised by O'Dwyer [18] and later developed by Block et al. [8], the evolution of this method represents one of the first rational approaches to the stability of masonry buildings and takes its steps from the analogy between the equilibrated shape of masonry arches and that of tensile suspended cables.

This analogy, known as the 'catenary principle', is that of an arc that is reminiscent of a long chain, retained at its ends and allowed to dangle (Figure 2). 


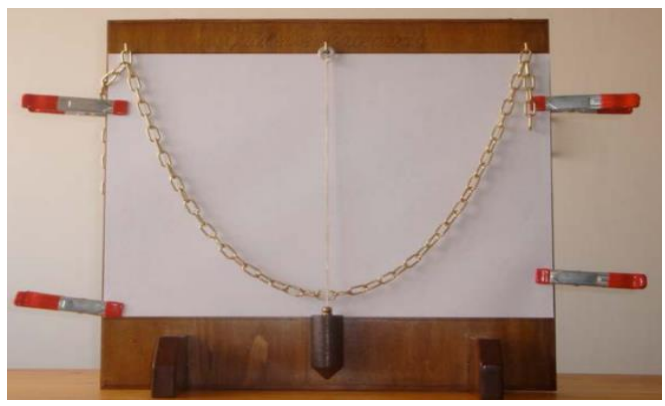

Figure 2. The catenary principle.

Heyman [19] combined this principle with the limit theorems of plasticity, specifically the static theorem, to evaluate the safety of masonry structures, predicting the ultimate mechanism of arches or 3D framed structures. An extension that includes domes and vaults was then proposed by O'Dwyer [18] in terms of fictitiously deconstructing the structure in discrete equilibrated arches, which entails seeking networks of forces inside the structure according to what has been denominated TNA.

A pictorial description of this idea is illustrated in Figure 3 , with reference to a cross vault exhibiting a comparatively simple static behaviour, with the two diagonal arcs providing the bearing structure that distributes the loads on the four pillars at the vertexes. The four columns support the four ribs of a barrel vault as a succession of increasingly smaller arcs from the external perimeter towards the centre. Each arch transmits its thrust connected to the diagonal arcs such that the diagonal arcs are loaded from the combination of the forces they sustain.

\section{BASICS OF THRUST NETWORK ANALYSIS}

According to the so-called safe theorem of limit analysis, in the form established by Heyman for masonry structures, the limit equilibrium of masonry vaults can be assessed by seeking a network of thrusts, i.e. purely compressive forces that are fully contained within the thickness of the vault and hence do not
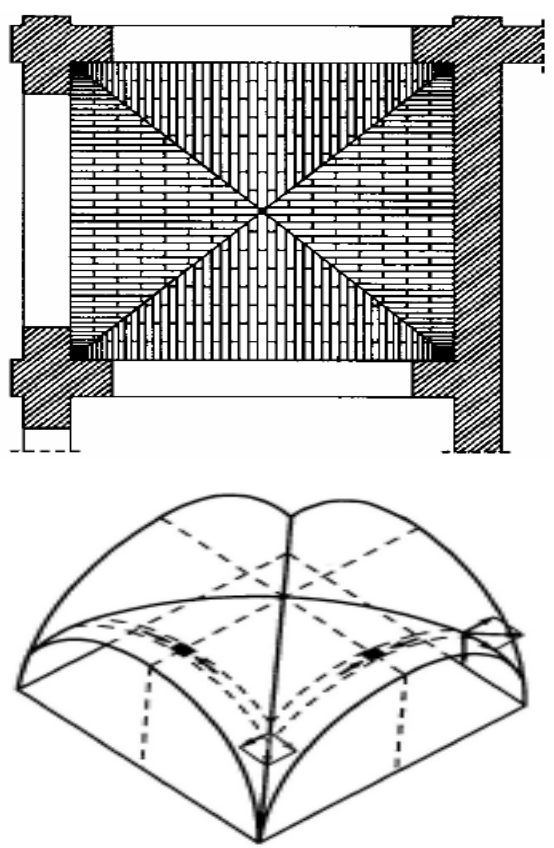

Figure 3. Plant and axonometric views of a masonry vault.

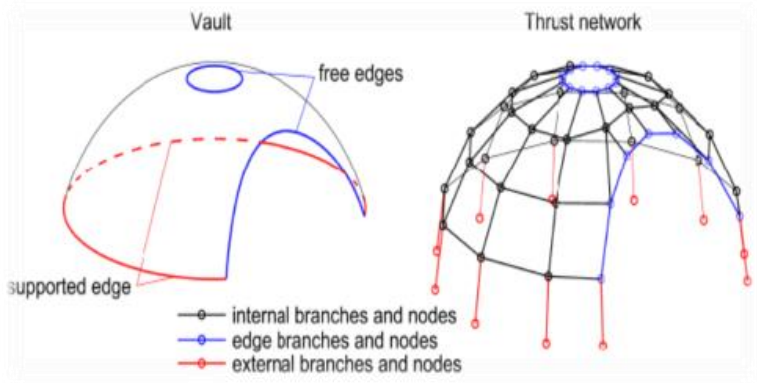

Figure 4. TNA modelling of the vault.

induce tensile stresses that masonry is incapable of withstanding. As such, the problem of identifying the maximum loads that a masonry vault can safety sustain is reconducted to identifying a specific set of points or nodes within the vault such that the applied loads are in equilibrium with the forces at each point, internal to the vault and purely compressive and directed along the fictitious branches connecting pairs of nodes.

The geometric position of these nodes is determined via an optimisation algorithm that enforces the condition whereby the initially unknown coordinates are contained within the vault thickness as well as in the branches connecting them (Figure 4).

Since the original paper [20] can be referred to for further details, in this paper, we detail only the simplest case of vertical loads by supplementing the original formulation with a simple example that will help the reader to grasp the details of the procedure (see Figure 5 and Figure 6).

The set of nodes and the related branches define a specific network, from now on referred to as a thrust network, which is described by $N_{n}$ nodes and $N_{b}$ branches that connect specific pairs of nodes. The $n$-th node of the network is defined by its position $\left(x_{n}, y_{n}, z_{n}\right)$, in a 3D Cartesian reference system, where $z$ is the vertical direction.

The external force concentrated at each node can be described as follows:

$$
f^{n}=\left(t_{x}^{n}, t_{y}^{n}, t_{z}^{n}\right)
$$

while the thrust value related to the generic branch can be denoted as:

$$
T^{(b)}=\left(t_{x}^{(b)}, t_{y}^{(b)}, t_{z}^{(b)}\right) .
$$

The set of nodes is split into $N_{i}$ internal nodes and $N_{r}$ restrained (or external) nodes, where only one external branch converges such that $N_{n}=N_{i}+N_{r}$, thus ensuring the external branches model supports the reactions.

The unknowns of the problem are represented by the coordinates of the nodes and thrusts within each branch. In fact, only the vertical coordinates of the nodes are sought since the

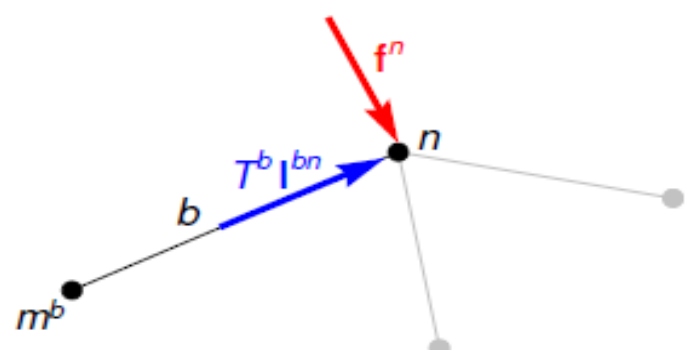

Figure 5. Equilibrium of nodes. 
horizontal coordinates are assigned by the designer by projecting the vault in the plane and defining a regular grid of points. Clearly, the disadvantage is the point distance, while the advantage is the quality of the analysis.

The $z_{n}$ coordinates of the nodes and the branch values $T^{b}$ are evaluated by enforcing an equilibrium at the internal and external nodes via two different strategies detailed separately here in terms of the horizontal and vertical direction.

\subsection{Horizontal equilibrium of nodes}

Denoted by $B_{n}$, the set of branches converging to node $n$, the horizontal equilibrium of the $n$-th node is expressed by the following equation:

$$
\begin{aligned}
& \sum_{b \in B_{n}} t_{x}^{(b)}+f_{x}^{(n)}=0 \\
& \sum_{b \in B_{n}} t_{y}^{(b)}+f_{y}^{(n)}=0
\end{aligned}
$$

in terms of the horizontal components $f_{x}^{n}, f_{y}^{n}$ of the external loads and the thrust forces $t_{x}^{b}, t_{y}^{b}$ relative to the branches $b$ connected to the node.

Indicated by $n$ and $m^{(b)}$, the indices of the nodes connected by the generic branch $b \epsilon B_{n}$ can be denoted by

$$
t_{h}^{(b)}=\sqrt{t_{x}^{(b)^{2}}+t_{y}^{(b)^{2}}}
$$

the horizontal component of the thrust, and by

$$
l_{h}^{(b)}=\sqrt{\left(x_{n}-x_{m}^{(b)}\right)^{2}+\left(y_{n}-y_{m}^{(b)}\right)^{2}}
$$

the length of the generic branch projected in the horizontal plane (see Figure 5).

Hence, we can evaluate the following:

$$
\frac{t_{x}^{(b)}}{t_{h}^{(b)}}=\frac{\left(x_{n}-x_{m}^{(b)}\right)}{l_{h}^{(b)}}
$$

and

$$
\frac{t_{y}^{(b)}}{t_{h}^{(b)}}=\frac{\left(y_{n}-y_{m}^{(b)}\right)}{l_{h}^{(b)}}
$$

which can be incorporated into Eq. 3 to get:

$$
\begin{aligned}
& \sum_{b \in B_{n}} \frac{\left(x_{n}-x_{m}^{(b)}\right)}{l_{h}^{(b)}} t_{h}^{(b)}+f_{x}^{(n)}=0 \\
& \sum_{b \in B_{n}} \frac{\left(y_{n}-y_{m}^{(b)}\right)}{l_{h}^{(b)}} t_{h}^{(b)}+f_{y}^{(n)}=0
\end{aligned}
$$

There is a large number of networks that are in equilibrium with a given set of external forces and, at the same time, are contained within the vault thickness. To address all of them in a comprehensive way, it is important to express the horizontal components of thrust $t_{h}^{(b)}$ as the product of a factor $\xi$ and various reference thrust values $\hat{t}_{h}^{(b)}$, both of which are left unspecified at the moment. Accordingly, for the generic $b$-th branch, we can set $t_{h}^{(b)}=\zeta \hat{t}_{h}^{(b)}=\frac{1}{r} \hat{t}_{h}^{(b)}$, and Eqs. 8-9 thus become: $\sum_{b \in B_{n}}\left[\frac{\hat{t}_{h}^{(b)}}{l_{h}^{(b)}} x_{n}-\frac{\hat{t}_{h}^{(b)}}{l_{h}^{(b)}} x_{m}^{(b)}\right]+f_{x}^{(n)} r=0$

$\sum_{b \in B_{n}}\left[\frac{\hat{t}_{h}^{(b)}}{l_{h}^{(b)}} y_{n}-\frac{\hat{t}_{h}^{(b)}}{l_{h}^{(b)}} y_{m}^{(b)}\right]+f_{y}^{(n)} r=0$

where the ratios $\frac{\hat{t}_{h}^{(b)}}{l_{h}^{(b)}}$ represent the reference thrust densities of the network branches.

\subsection{Vertical equilibrium of nodes}

Recalling that $t_{z}^{(b)}$ and $f_{z}^{(n)}$ are, respectively, the vertical component of the $b_{t h}$ branch thrust converging to node $n$ and the nodal load, the vertical equilibrium of a generic node can be written as follows:

$\sum_{b \in B_{n}} t_{z}^{(b)}+f_{z}^{(n)}=0$

Now, recalling that, if compressive, thrust force $\mathbf{t}^{(\mathrm{b})}$ is oriented towards node $n$, we have the following:

$$
\begin{aligned}
t_{z}^{(b)} & =\frac{t_{h}^{(b)}}{l_{h}^{(b)}}\left(z_{n}-z_{m}^{(b)}\right) \\
& =\zeta \frac{\hat{t}_{h}^{(b)}}{l_{h}^{(b)}}\left(z_{n}-z_{m}^{(b)}\right)=\frac{1}{r} \frac{t_{h}^{(b)}}{l_{h}^{(b)}}\left(z_{n}-z_{m}^{(b)}\right)
\end{aligned}
$$

where the formula $t_{h}^{(b)}=\zeta \hat{t}_{h}^{(b)}=\frac{1}{r} \hat{t}_{h}^{(b)}$ has been used.

Accordingly, Eq. 13 can be rewritten as follows:

$$
\sum_{b \in B_{n}} \frac{z_{n}-z_{m}^{(b)}}{l_{h}^{(b)}} \hat{t}_{z}^{(b)}+f_{z}^{(n)} r=0
$$

or equivalently as

$$
\sum_{b \in B_{n}}\left[\frac{\hat{t}_{h}^{(b)}}{l_{h}^{(b)}} z_{n}-\frac{\hat{t}_{h}^{(b)}}{l_{h}^{(b)}} z_{m}^{(b)}\right]+f_{z}^{(n)} r=0 .
$$

The previous condition is used to evaluate the unknown nodal heights $z_{\mathrm{n}}$, the coefficients of which are expressed by means of the reference thrust densities.

The physical meaning of the parameter $\xi=\frac{1}{r}$ is exemplified by the three-hinged arch shown in Figure 6, for which the equilibrium needs to be written only for the central node.

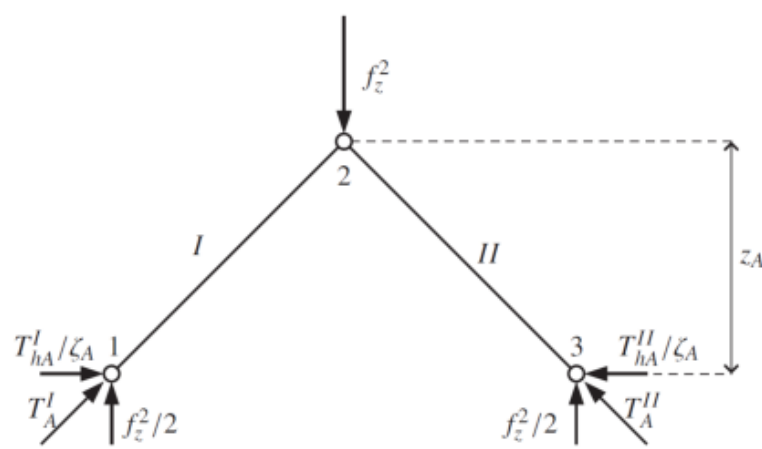

Figure 6. Illustrative example of the vertical equilibrium of a node. 
Given that $z_{m}^{(b)}=0$, Eq. 15 can be simplified to $\frac{\hat{t}_{h}^{(b)}}{l_{h}^{(b)}} z_{n}+$ $f_{z}^{(n)} r=0$ or, equivalently, given that $f_{z}^{(n)}<0$ since it is directed downwards, to

$$
\left|f_{z}^{(n)}\right| r=\frac{\hat{t}_{x}^{(b)}}{l_{h}^{(b)}} z_{n}
$$

Given that $t_{h}^{(b)}, l_{h}^{(b)}$ are both positive, it can be inferred that a greater value of $r$ is associated with a greater value of $z_{n}$ and vice versa.

This, in turn, implies that we are seeking networks with the uppermost vertical coordinates of all nodes and, hence, the minimum thrust.

\section{CASE STUDY}

The present case study relates to the laser scanning survey for the Santa Maria della Libera church in the municipality of Aquino, and the attendant structural analysis for the static verification of the church's cross vaults [20].

The church, which dates from 1000-1100 A.D. and is characterised by a pure Romanic-Benedictine style, was built with the typical 'local soft' travertine, fragmentary material of the remains of Roman buildings surrounding the area where it was erected.

The amazing and austere interior, with dimensions of $17 \times$ $38 \mathrm{~m}$, consists of three aisles divided by square pillars with three semi-circular absids and an imposing triumphal arch, also resting on pillars culminating with fragments of Roman cornice that act as capitals, which leads to the transept (Figure 7, Figure 8).

Meanwhile, the main altar, consisting of a Roman marble sarcophagus, is placed in the centre, with the centre aisle having a wooden roof, while the side aisles feature various cross vaults.

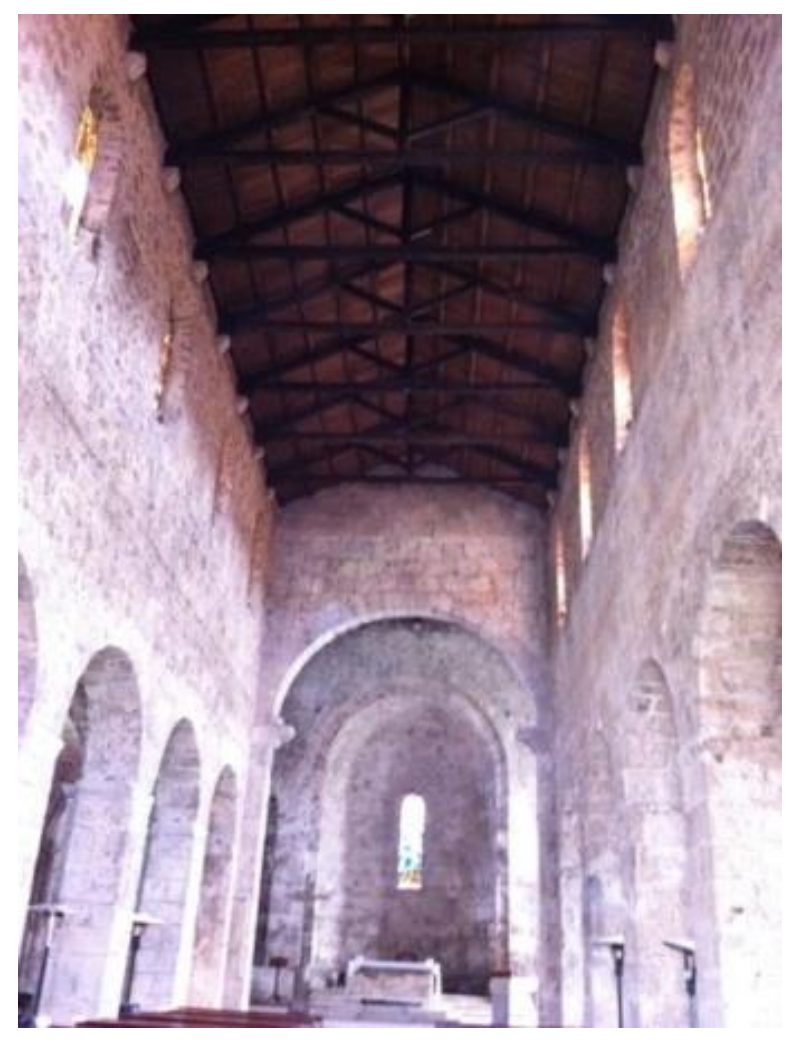

Figure 7. Image of the central nave.

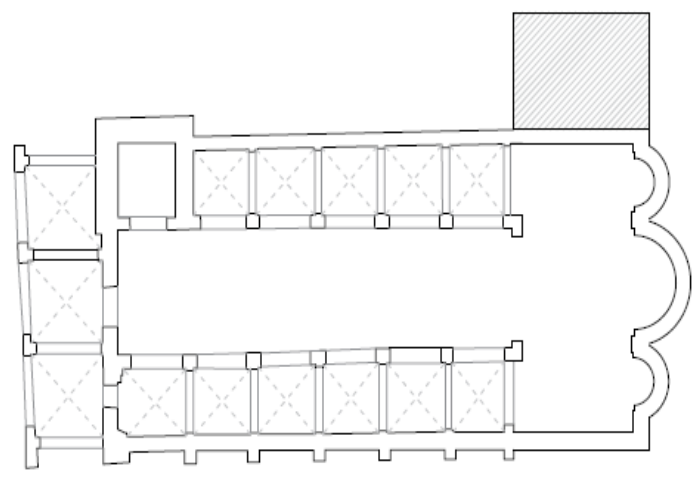

Figure 8. Internal plan.

The campaign of measurements was focused on the interior and exterior of the masonry structure, with its geometry and external projections making the survey particularly complex and cumbersome. In fact, the vaults in the interior aisles of the church have been the subject of various detailed studies [21]-[27].

First, an accurate topographical survey of the historic artifact's site was carried out using the TOPCON GLS-2000 laser scanner station (Figure 9). During a four-hour period, 16 scans were performed at different station points in order to obtain an extremely high density of scan points, approximately five million points with measured coordinates with millimetre accuracy [20].

The survey was divided into several phases after careful planning of the campaign and the identification of the station points. The design of the survey included maps from Google Maps with on-site identification, cloud capture scans of specific points detected by a laser beam with a $360^{\circ}$ horizontal and $270^{\circ}$ vertical range of action, scanning alignment in pairs, global alignment, filtering, modelling, and editing in terms of the subroutine that the TNA code was connected to (Figure 10). Point cloud models obtained using a survey method

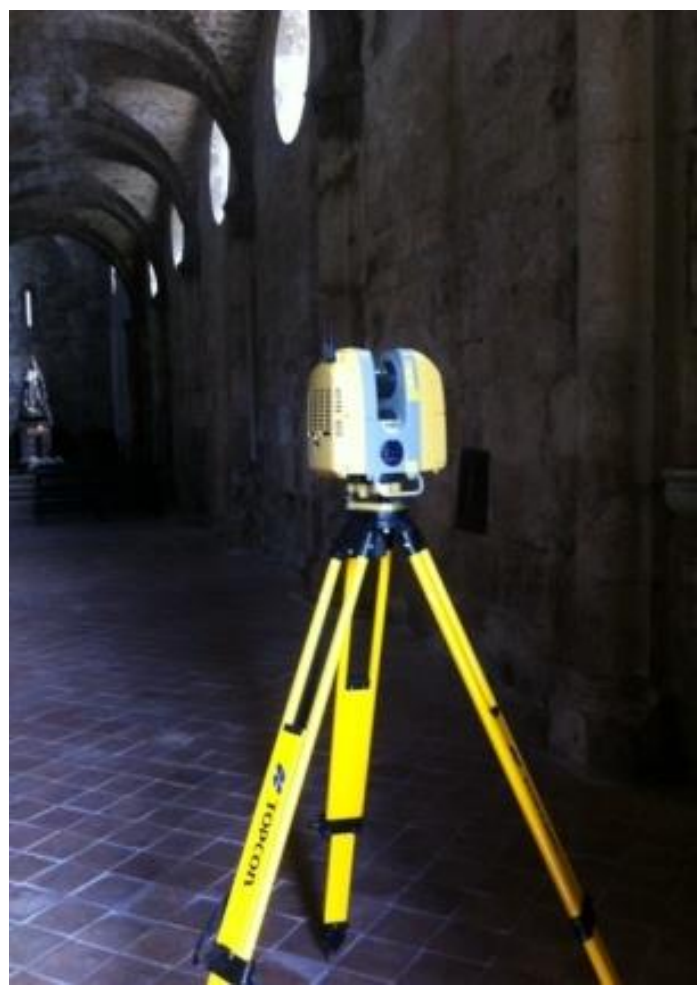

Figure 9. Image of the lateral left nave with a view of the masonry cross vaults. 


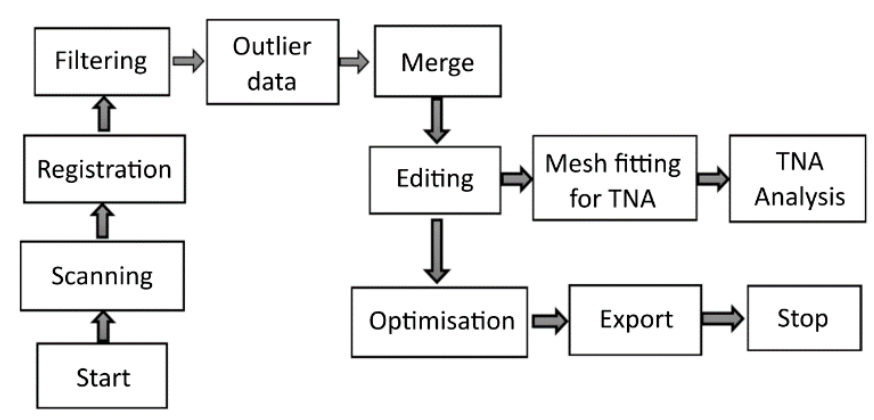

Figure 10. Flowchart of the scan-to-BIM process.

incorporating high-precision laser scanning instruments have certain limitations from a computational point of view. In fact, it is not possible to directly associate the physical behaviour of the model derived from a point cloud using structural software.

In fact, the transition from a point cloud to a polygonal surface model can be defined as a 're-topology' operation since both quantitative and qualitative information of the point's model are translated and adapted to obtain a triangular or quadrangular mesh that better represents the polygonal surface. Meanwhile, the structural analysis software uses an algorithm that requires the geometric dimensions of the masonry object as the input data.

The laser scanning survey consists of assigning a triplet of $x y z$ coordinates to each point, with the coordinates initially relative before becoming absolute through a geo-referencing operation. In order to extrapolate the coordinates of the points, the Cloud Compare software offered us both the possibility of querying the single point or selecting a number of $n$ points and exporting the list in .txt formats.

Once the data had been extrapolated and processed, they were exported to an Excel table. In fact, the masonry elements are typically non-regular and non-continuous, do not have a homogeneous surface, and are made of masonry ashlars that are not perfectly squared. Accordingly, the geometric data obtained from the survey needed to be appropriately smoothed to achieve more regular surfaces, i.e. surfaces with no kinks, unrealistic holes, or superposition patches.

In order to resolve this problem and to obtain coordinates that allowed us to provide correct geometric data for processing via the structural algorithm, an interpolating function was built. Specifically, the following polynomial formula was chosen to interpolate the curve drawn with the coordinates of the surveyed points in the best way possible.

The equation of the polynomial formula is:

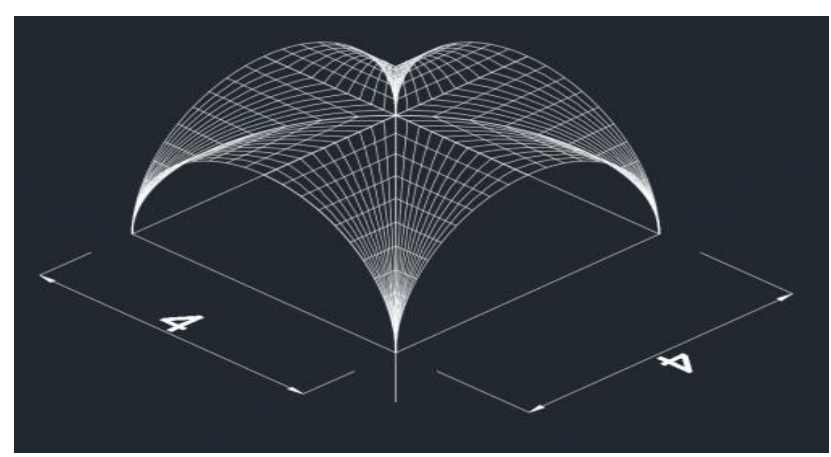

Figure 11. Medium surface of the vault geometry obtained via the surveying of the intrados and discrete measurements of the vault thickness.
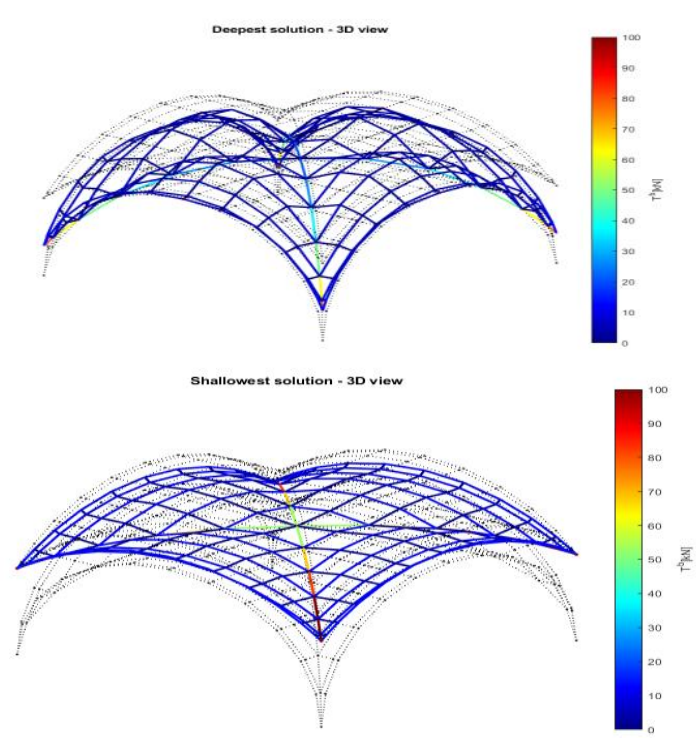

Figure 12. Distribution of maximum and minimum thrusts within the vault.

$$
\begin{aligned}
y= & -0.0236 x^{6}+0.023 x^{5}+0.0677 x^{4}-0.0597 x^{3} \\
& -0.3024 x^{2}+0.1172 x+12.871 .
\end{aligned}
$$

The regression line represented a good fit of the points as the index of variance of the line demonstrated, with a value of $R^{2}=$ 0.9974 , i.e. very close to one.

\section{RESULTS}

The application of the TNA method, illustrated here for a single cross vault of the roof, was extended to the static and structural verification of all masonry vaults existing in the $\mathrm{S}$. Maria della Libera Church in Aquino.

Each of the church's cross vaults in the aisles has a square base whose side length is equal to 4 meters, a height equal to 2 meters, a thickness of 0.45 meters and it is made of soft travertine with a specific weight of $2.72 \mathrm{t} / \mathrm{m}^{3}$ (Figure 11).

The application of the TNA method to a single cross vault provided, as can be seen from Figure 12 and Figure 13, the minimum and maximum thrust values of each of the 389 branches of the cross vaults, as well as the minimum and maximum values of the height of each of the 222 nodes of the roof associated with the maximum and minimum thrust values.

The maximum height of the network nodes that characterises the deepest limit configuration, i.e. that associated with the minimum thrust, was $2.48 \mathrm{~m}$. Conversely, the shallowest limit configuration, associated with the maximum thrust, had a value of $1.38 \mathrm{~m}$ as the minimum node height.

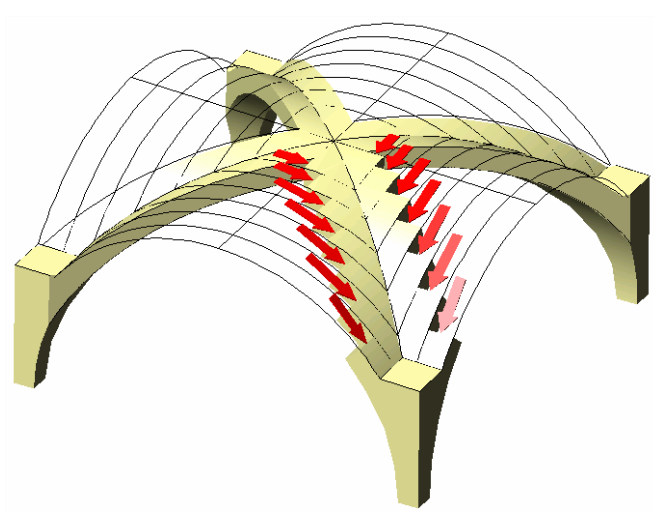

Figure 13. Thrust distribution in a rib. 


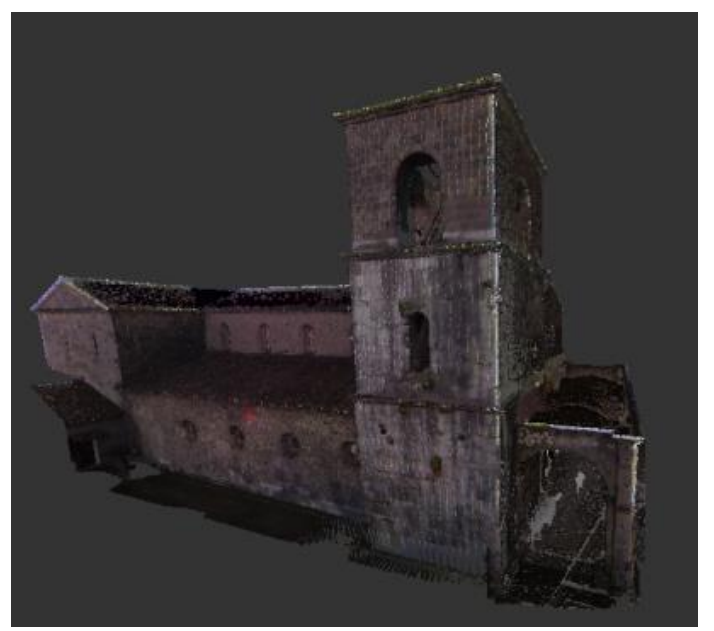

Figure 14. 3D digital model of an external side of the S. Maria della Libera Church.

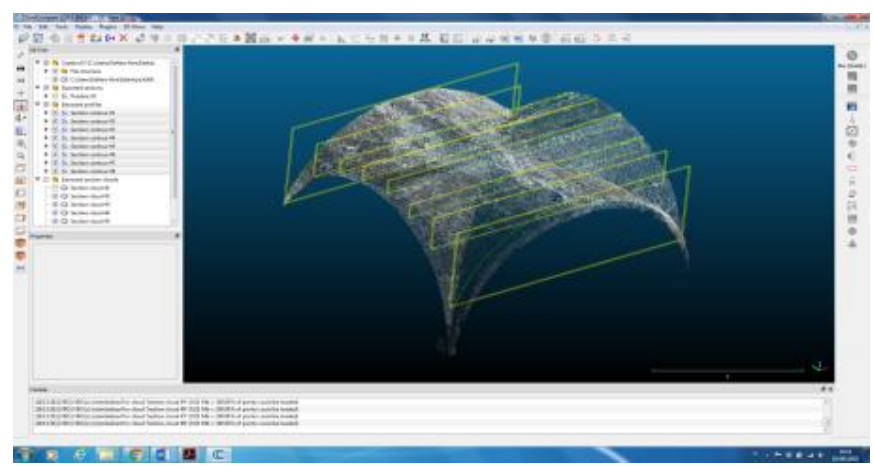

Figure 15. Export sections from Cloud

\section{CONCLUSIONS}

The TLS survey carried out on the monumental complex of the Church of Santa Maria della Libera in Aquino provided the point cloud required to perform a structural modelling of the church's masonry vaults using the TNA approach.

The geometric and geo-referenced 3D model obtained by processing the laser-scanning measurements presented a model built on a coherent geometric basis, which considers the methodological complexities of the detected object (Figure 14 and Figure 15).

The paper demonstrated how the interdisciplinarity between a geometric model, built with the innovative techniques typical of the geomatic-type survey, and a structural model, can represent a useful support to the structural verification of the safety and conservation of complex structures, such as those typically pertaining to the field of monumental heritage.

In future research within this reference context, HBIM models will be addressed, which are part of a semi-automated method that allows for switching from point cloud to an advanced 3D model with the capacity to contain all the geometrical and mechanical characteristics of the built object [28]-[34].

Moreover, FEM analyses, based on recently developed strategies related to masonry modelling [35]-[37], will be investigated in order to assess the outcomes of the TNA.

\section{ACKNOWLEDGMENTS}

This work has been carried out under the GAMHer project: Geomatics Data Acquisition and Management for Landscape and Built Heritage in a European Perspective, PRIN: Progetti di Ricerca di Rilevante Interesse Nazionale - Bando 2015, Prot. 2015HJLS7E. GAMHer, URL: https://site.unibo.it/gamher/en.

\section{REFERENCES}

[1] R. Quattrini, F. Clementi, A. Lucidi, S. Giannetti, A. Santoni, From TLS to FE analysis: points cloud exploitation for structural behaviour for definition. The San Ciriaco's bell tower, The Int. Archives of the Photogrammetry, Remote Sensing and Spatial Information Sciences, Vol. XLII-2/W15, 2019 27th CIPA Int. Symp. Documenting the past for a better future, Ávila, Spain, 1-5 September 2019, pp. 957-964.

DOI: $\underline{10.5194 / \text { isprs-archives-XLII-2-W15-957-2019 }}$

[2] T. Ramon Herrero-Tejedor, F. Arques Soler, S. Lopez-Cuervo Medina, M. R. de la O Cabrera, J. L. Martìn Romero, Documenting a cultural landscape using point-cloud 3D models obtained with geomatic integration techniques. The case of the El Encin atomic garden, Madrid (Spain), PLOS ONE 15(6), 24 June 2020, e0235169, 16 pp.

DOI: $10.1371 /$ journal.pone.0235169

[3] P. Roca, M. Cervera, G. Gariup, L. Pela, Structural Analysis of Masonry Historical Constructions. Classical and Advanced Approaches Architectural Computation Methods Engineering, Springer, Cham., 2010, pp. 299-325. DOI: $10.1007 / \mathrm{s} 11831-010-9046-1$

[4] G. Roca, F. Lopez-Almansa, J. Miquel, A. Hanganu, Limit analysis of reinforced masonry vaults, Engineering Structures 29 (2007) 3, pp. 431-439.

DOI: $10.1016 /$ j.engstruc.2006.05.009

[5] G. Bitelli, C.Balletti, R. Brumana, L. Barazzetti, M. G. D'Urso, F. Rinaudo, G.Tucci, The GAMHer Research project for metric documentation of cultural heritage: current developments, The Int. Archives of the Photogrammetry, Remote Sensing and Spatial Information Sciences, Vol. XLII-2-W11-, Proc. of 2019GEORES and 2019-2nd International Conference of Geomatics and Restoration, 8 - 10 May 2019, Milan, Italy, pp. 239-246; DOI: $10.5149 /$ isprs -archives-XLII-2-W11-239-2019

[6] G. Bitelli, C. Balletti, R. Brumana, L. Barazzetti, M.G. D'Urso, F. Rinaudo, G.Tucci, Metric documentation of cultural heritage: research directions from the Italian GAMHer Project, The Int. Archives of the Photogrammetry, Remote Sensing and Spatial Information Sciences, Vol. XLII-2-W5, 2017, pp. 83-89; DOI: $10.5149 /$ isprs -archives-XLII-2-W5-83-2017

[7] G. Bitelli, G. Castellazzi, A. M. D’Altri, S. De Miranda, A. Lambertini, I. Selvaggi, Automated voxel model from point clouds for structural analysis of cultural heritage, The Int. Archives of the Photogrammetry, Remote Sensing and Spatial Information Sciences, Vol. XLI-B5, XXIII ISPRS Congress, Prague, Czech Republic, 12-19 July 2016. DOI: $10.5194 /$ isprsarchives-XLI-B5-191-2016

[8] A. Georgoupolos, Ch. Ioannidis, 3D visualization by integration of multi-source data for monument geometric recording, in: Recording, Modeling and Visualization of Cultural Heritage, Baltsavias et al. (editors), Taylor \& Francis Group, International Workshop, Ascona, 2005. ISBN 041539208 X

[9] C. Brito, N. Alves, L. Magalhães, M. Guevara, BIM mixed reality tool for the inspection of heritage building, ISPRS Ann. Photogramm. Remote Sens. Spatial Inf. SCI, IV-2/W6, pp. 25-29. DOI: $10.5194 /$ isprs-annals-IV-2-W6-25-2019

[10] S. Logothetis, A. Delinasiou, E. Stylianidis, Building information modelling for cultural heritage: a review, ISPRS Annals of the Photogrammetry; Vol. II-5/W3, 25 th Int. CIPA Symposium, Taipei, Taiwan, 31 August -4 September 2015, pp. 177-183. DOI: $10.5194 /$ isprsannals-II-5-W3-177-2015 
[11] A. Georgoupolos, D. Delikaraoglou, Ch. Ioannidis, E.Lambrou, G.Pantazis, Using geodetic and laser scanner measurements for measuring and monitoring the structural damage of a post Byzantine church, $8^{\text {th }}$ Int. Symp. on Conservation of Monuments in the Mediterranean Basin, Monument damage Hazards and Rehabilitation Technologies, Patras, Greece, 31 May-2 June 2010.

[12] F. Marmo, L. Rosati, Reformulation and extension of the thrust network analysis, Comp. \& Struct. 1822 (2017), pp. 104-118. DOI: $10.1016 /$ i.compstuc.2016.11.016

[13] F. Marmo, D. Masi, L. Rosati, Thrust network analysis of masonry helical staircases, Int. J. of Arch. Her. 12(5) (2018), pp. 828-848. DOI: $\underline{10.1080 / 15583058.2017 .1419313}$

[14] F. Marmo, D. Masi, D. Mase, L. Rosati, Thrust network analysis of masonry vaults, Int. J. of Masonry Res. and Innov. 4 (2019), pp. 64-77. DOI: $10.1504 /$ IJMRI.2019.096828

[15] F. Marmo, N. Ruggieri, F. Toraldo, L. Rosati, Historical study and static assessment of an innovative vaulting technique of the $19^{\text {th }}$ century, Int. J. of Arch. Her., 13(6) (2019), pp. 799-819. DOI: $\underline{10.1080 / 15583058.2018 .1476607}$

[16] F. Marmo, M. Marmo, S. Sessa, A. Pagliano, L. Rosati, Thrust membrane analysis of the domes of the baia thermal baths, In: Carcaterra A., Paolone A., Graziani G. (editors), Proc. of XXIV AIMETA Conf., Rome, Italy, 15-19 September 2019, Lect. Notes Mech. Engrg. Springer, 2019, ISBN 978-3-030-41057-5. DOI: $10.1007 / 978-3-030-41057-5 \quad 154$

[17] F. Marmo, D. Masi, S. Sessa, F. Toraldo, L. Rosati, Thrust network analysis of masonry vaults subject to vertical and horizontal loads, Proc. $6^{\text {th }}$ Int. Conf. on Comp. Methods in Structural Dynamics and Earthquake Eng. COMPDYN 2017, Rhodes Island, Greece, 15-17 June 2017, pp. 2227-2238. DOI: $10.7712 / 120117.5562 .17018$

[18] D. O'Dwyer, Funicular analysis of masonry vaults, Comp. \& Struct. 73 (1999), pp. 187-197.

[19] J. Heyman, The masonry arch, Ellis Horwood, 1982, pp.85-90.

[20] M. G. D'Urso, V. Manzari, B. Marana, Terrestrial laser-scanning point clouds for modeling masonry vaults, Proc. of IMEKO TC4 Int. Conf. on Metrology for Archaeology and Cultural Heritage, 46 December 2019, Florence, Italy, pp. 282-286. Online [Accessed 22 March 2021]

https://www.imeko.org/publications/tc4-Archaeo2019/IMEKO-TC4-METROARCHAEO-2019-52.pdf

[21] M. G. D'Urso, E. Corsi, C. Corsi, Mapping of archaeological evidences and 3D models for the historical reconstruction of archaeological sites, Metrology for Archaeology and Cultural Heritage (MetroArchaeo), Cassino FR, Italy, 22-24 October 2018, pp. $437-442$.

DOI: $10.1109 /$ MetroArchaeo43810.2018.9089783

[22] M. G. D’Urso, E. Corsi, S. Nemeti, M. Germani, From excavations to Web: A GIS for archaeology, The Int. Archives of the Photogrammetry, Remote Sensing and Spatial Information Sciences, Vol. XLII-5/W1, Geomatics \& RestorationConservation of Cultural Heritage in the Digital Era, Florence, Italy, 22-24 May 2017, pp. 219-226. DOI: $10.5194 /$ isprsarchives- XLII-5/W1-219-2017

[23] M. G. D'Urso, C. L. Marino, A. Rotondi, On 3D dimension: study cases for archaeological sites, The Int. Archives of the Photogrammetry, Remote Sensing and Spatial Information Sciences, Vol. XL-6 (2008), pp. 13-18, ISSN: 1682-1750. DOI: $10.5194 /$ isprsarchives XL-6-13-18

[24] M.G. D'Urso, G. Russo, On the integrated use of laser-scanning and digital photogrammetry applied to an archaeological site, The Int. Archives of the Photogrammetry, Remote Sensing and Spatial Information Sciences. Vol. XXXVII-B5-2/Comm.V, ISSN 1682 1750, ISPRS, Beijing, China, 3-11 July 2008, pp. 1107-1112.

[25] S. Parrinello, R. De Marco, Integration and modelling of 3D data as strategy for structural diagnosis in endangered sites. The study case of Church of the Annunciation in Pokcha (Russia), IMEKO TC4 Int. Conf. on Metrology for Archaeology and Cultural Heritage, Florence, Italy, 4-6 December 2019, pp. 223-228. Online [Accessed 22 March 2021] https://www.imeko.org/publications/tc4-Archaeo2019/IMEKO-TC4-METROARCHAEO-2019-41.pdf

[26] A. Piemonte, G. Caroti, I. Martínez-Espejo Zaragoza, F. Fantini, L. Cipriani, A methodology for planar representation of frescoed oval domes: formulation and testing on Pisa Cathedral ISPRS, Int. J. Geo-Information 7 (2018), p. 318.

DOI: $10.3390 /$ ijgi7080318.

[27] B. Riveiro, B. Conde-Carnero, H. González-Jorge, P. Arias, J. C. Caamaño, Automatic creation of structural models from point cloud data: the case of masonry structures, ISPRS Annals of the Photogrammetry; Vol. II-3/W5 Geospatial Week, 2015, pp. 3-9. DOI: $\underline{10.5194 / \text { isprsannals-II-3-W5-3-2015 }}$

[28] G. Guidi, F. Remondino, M. Russo, F. Menna, A. Rizzi, S. Ercoli, A multi-resolution methodology for the 3D modeling of large and complex archeological areas, International Journal of Architectural Computing (IJAC) Special Issue (2009), pp. 39-55.

[29] M. Hess, V. Petrovic, M. Yeager, F. Kuester, Terrestrial laser scanning for the comprehensive structural health assessment of the Baptistery di San Giovanni in Florence, Italy: an integrative methodology for repeatable data acquisition, visualization and analysis, Structure and Infrastr. Eng. 14(2) (2018), pp. 247-263. DOI: $\underline{10.1080 / 15732479.2017 .1349810}$

[30] M. C. L. Howey, M. Brouwer Burg, Assessing the state of archaeological GIS research: Unbinding analyses of past landscapes, Journal of Archaeological Science 15(5) 2017, pp. 1-9. DOI: $10.1016 /$ i.jas.2017.05.002

[31] L. C. Hung, W. Xiangyu, J. Yi, BIM-enabled structural design: impacts and future developments in structural modelling, Analysis and Optimisation Processes, Arch. Computat. Methods 22 (2015), pp. 135-151.

DOI $10.1007 / \mathrm{s} 11831-014-9127-7$

[32] M. Llobera, Building past landscape perception with GIS: Understanding topographic prominence, Journal of Archaeological Science 28 (2001), pp. 1005-1014. DOI: $10.1016 /$ jasc. 2001.0720

[33] A. Mitropoulou, A. Georgopoulos, An automated process to detect edges in unorganized point clouds, ISPRS Ann. Photogramm. Remote Sens. Spatial Inf. Sci., Vol. IV-2/W6, (2019), pp. 99-105.

DOI: $10.5194 /$ isprs-annals-IV-2-W6-99-2019

[34] X. Yang, M. Koehl, P. Grussenmeyer, Parametric modelling of asbuilt beam framed structure in BIM environment The Int. Archives of the Photogrammetry, Remote Sensing and Spatial Information Sciences, Volume XLII-2/W3, 2017 3D Virtual Reconstruction and Visualization of Complex Architectures, Nafplio, Greece, 1-3 March 2017, pp. 651-657. DOI: $10.5194 /$ isprs-archives-XLII-2-W3-651-2017

[35] R. Serpieri, S. Sessa, L. Rosati, A MITC-based procedure for the numerical integration of a continuum elastic-plastic theory of through-the-thickness-jacketed shell structures, Comp. Struct., 1912018 pp. 209-220. DOI: $10.1016 /$ i.compstruct.2018.02.031

[36] S. Sessa, R. Serpieri, L. Rosati, A continuum theory of throughthe-thickness jacketed shells for the elasto-plastic analysis of confined composite structures: Theory and numerical assessment, Comp. part B: Eng., 113 (2017), pp. 225-242.

DOI: 10.1016/j.compositesb.2017.01.011

[37] S. Sessa, R. Serpieri, L. Rosati, Probabilistic assessment of historical masonry walls retrofitted with through-the-thickness confinement devices, Proc. of $23^{\text {rd }}$ AIMETA Conf., Salerno, Italy, 4-7 September 2017, pp. 2324-2332. 